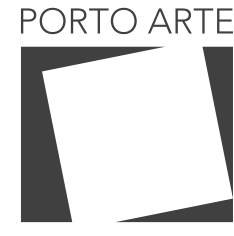

Revista de Artes Visuais

v.25 n. 43

Jan/jun 2020 e-ISSN: 2179-8001

\section{Textos curatoriais na virada 1960/1970: meio-ambiente informacional}

\author{
Curatorial texts in the 1960/1970 turn: informational milieu
}

\section{Ruy Cézar Campos Figueiredo}

ORCID: 0000-0001-8339-6634

Universidade do Estado do Rio de Janeiro

\section{Resumo}

A experiência expositiva mediada por computadores em rede atingiu um curioso pico de relação com teorias e sistemas de informação diante das circunstâncias criadas pela pandemia do vírus COVID-19, sendo sadio o gesto reflexivo de observar aspectos precedentes das relações entre arte e pensamento gestado em ambien-

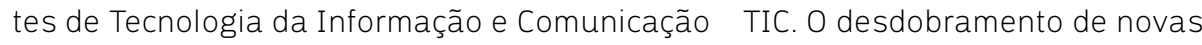
teorias e tecnologias sobre informação durante e após a Segunda Guerra Mundial foi um gatilho do que culminou com o estabelecimento e desenvolvimento da cibernética, das linguagens de programação e dos primeiros experimentos com redes de computadores. 0 artigo discute textos curatoriais de exposições que envolvem práticas conceituais com tecnologias de informação na virada de década 1960/1970.

Palavras-chave:

Informação. Cibernética. Texto curatorial. Prática conceitual.

\section{Abstract}

The exhibitional experience mediated by network computers hit, amid the COVID-19 pandemics, a singular peak. It is healthy the reflexive gesture of observing preceding aspects of relations between art and thinking gestated in Information and Communication Technologies environments. The unfoldment of new theories and technologies about information during and after the Second World War was a trigger to what culminated in the establishment and development of cybernetics, programming languages and the first experiments with computer networks. The appearance of conceptual practices in arts is intrinsically tied to the modes of relating with information and its circulation. The article here, therefore, turns to situate and discuss curatorial texts of exhibitions relating conceptual practices with information technologies along the 1960/1970's turn.

Keywords:

Information. Cybernetics. Curatorial text. Conceptual practice. 


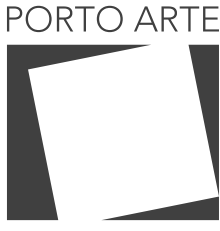

Revista de Artes Visuais

$\vee 25 n .43$

Jan/jun 2020 e-ISSN: 2179-8001

\section{Introdução}

A cibernética emerge entre as décadas de 1940 e 1950 como um campo interdisciplinar neural para as mudanças sociais e culturais catalisadas após a Segunda Guerra Mundial. Tal período marca a linha divisória entre a era industrial moderna e a era pós-industrial de computadores e tecnologias de rede.

As "Conferências Macy em Cibernética" (1946-1953) e o livro Cybernetics: or Control and Communication in The Animal and The Machine, publicado em 1948 por Norbert Wiener, deram corpo à uma ciência pautada em sistemas de retroalimentação informacional. Tais são marcos de um contexto que, seguindo Parikka (2010), é reconhecido por reconfigurar as conexões existentes entre os humanos e as máquinas, repercutindo no desenvolvimento dos computadores, nas ciências da informação e no interesse pelo controle de sistemas vivos (compreendidos como entidades de informação).

Escrevendo em 1969, Marshall McLuhan chama atenção para como os primeiros exploradores desse campo científico o definiram etimologicamente a partir da palavra do grego antigo kubernētēs, cujo sentido está relacionado à arte de conduzir, navegar, dirigir. Começou-se a dar vazão, nesse período, para o "oceano de informação" inundar a vida cotidiana de populações. Navegamos hoje por esse mar através de timelines e relações de dados institucionais, sociais, biológicas, culturais, infraestruturais.

Entre 1960 e 1970, todavia, já era claro para McLuhan que "a aceleração do movimento da informação cria um ambiente de "sobrecarga informacional" que demanda, para a sobrevivência humana, padrões de reconhecimento" (MCLUHAN, 1969, pp. 5-6; trad. livre). Com a criação de um "ambiente informacional", as consequências dessa sobrecarga teriam, para McLuhan, efeitos políticos e econômicos imprevisíveis.

A arte não tardou, nesse cenário, a também ser enquadrada por práticas e discursos críticos ou anedóticos que buscaram a reposicionar diante desse contexto. Shanken (2002, p. 437) aponta, todavia, que a historicização da arte ainda carece de estudos que explorem as relações de proximidade e cruzamento entre tecnologias da informação, suas teorizações, as práticas artísticas conceituais e a arte computacional:

Respeitando-se as diferenças entre essas tendências artísticas e ao mesmo tempo se entendendo alguns dos fios teóricos compartilhados em comum por elas, pode ser formulada uma leitura mais compreensiva da arte feita desde a metade do século XX (SHANKEN, 2002, p. 438; trad. livre).

0 artigo aqui apresentado, nesse sentido, volta-se para situar e discutir projetos e textos curatoriais de exposições que envolvem práticas conceituais com tecnologias de informação na virada de década 1960/1970: "Cybernetic Serendipity" (1968), exposição ocorrida no Institute of Contemporary Art de Londres com curadoria de Jasia Reichardt; "Information" (1970), que ocorreu no Museu de Arte Moderna - MoMa em 


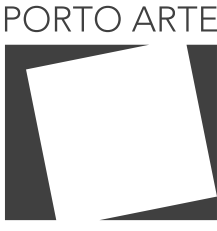

Revista de Artes Visuais

$\vee 25 n .43$

Jan/jun 2020 e-ISSN: 2179-8001

Nova Iorque, com curadoria de Kynaston McShine; "Software. Information Technology: its new meanings for art" (1970), realizada no Jewish Museum em Nova Iorque com curadoria de Jack Burnham; e "Arteônica" (1971), realizada na Fundação Armando Álvares Penteado, com curadoria de Waldemar Cordeiro.

O período da virada 1960/1970 marca, seguindo Gere (2009, p. 106), tanto o apogeu quanto o começo do fim de uma intensa relação entre a cibernética e a arte contemporânea. Tal relação, aqui no Brasil, manifestou-se no concretismo de artistas como Waldemar Cordeiro e, ainda que certamente não tenha cessado na década de 1980 , intensificou-se mais vertiginosamente em um cenário global apenas na virada $1990 / 2000$, com a emergência comercial da World Wide Web e uma prolífica ramificação de experiências com arte digital no país.

Em 2020, os meios computacionais e informacionais acabaram sendo o que restou possível para o circuito das artes buscar se manter em atividade durante a pandemia do vírus COVID-19, proliferando-se exposições online e expectativas de inovação digital na dinâmica comercial que, em alerta, teme colapsar.

Com o recorte do artigo, objetiva-se destacar como os curadores apresentavam, nos textos de catálogo, as relações entre os sistemas de informação e as questões da arte, bem como apontavam na atenção para as tecnologias emergentes um possível caminho solucionador de crises e problemas dos meios artísticos modernos. Colabora-se, nesse sentido, com o pensamento sobre períodos de deslumbre curatorial entre arte e sistemas de informação. Tal pensamento tende a se expandir e ganhar melhor compreensão crítica diante dos desdobramentos possíveis da atual crise, bem como diante da diversificação de arranjos que as pesquisadoras e pesquisadores virão a compor para refletir sobre tal tema na década de 2020.

\section{Cybernetic Serendipity}

Foram três anos de planejamento, viagem e angariamento de fundos que mobilizaram, na segunda metade da década de 1960, Josia Reichardt para apresentar as possíveis relações entre arte e ciência da cibernética. "Cybernetic Serendipity" (1968) é introduzida no seu catálogo como uma exposição de possibilidades, mais do que de conquistas, tendo como finalidade apresentar uma área de atividade que manifestava o envolvimento tanto de artistas com ciência quanto de cientistas com arte.

Durante o período de pré-produção, a curadora teve as portas abertas para o mundo industrial de gigantes corporativos como Boeing e General Motors, conforme carregava uma carta de apresentação assinada pela IBM norte-americana. A exposição, afinal, ocorreu no Institute of Contemporary Art em Londres e contou com cerca de 325 participantes de diversos países, variando o número de visitantes entre 45,000 e 60,000 , sem, contudo, apresentar computadores em seu espaço expositivo. A abertura contou com a presença do ministro de tecnologia do Reino Unido e teve cobertura positiva da grande imprensa (como o jornal Daily Mirror e a revista Vogue), contando 


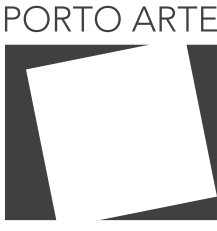

Revista de Artes Visuais

$\vee 25 n .43$

Jan/jun 2020 e-ISSN: 2179-8001

posteriormente com uma problemática itinerância em menor escala1, exposta na Corcoran Gallery em Washington e no Exploratorium, um museu de ciência e arte em São Francisco (USSELMANN, 2013).

A versão completa da exposição estava dividida em três seções: 1. gráficos gerados por computadores, filmes animados por computadores e músicas e poemas compostos por computadores. 2. Dispositivos cibernéticos, ambientes cibernéticos expostos como obras de arte, bem como máquinas de pintura controladas remotamente. 3. Máquinas demonstrando o uso de computadores e um ambiente contextualizando a história da cibernética.

Para o catálogo da exposição, Reichardt (1969) editou uma edição especial da revista Studio International, com 300 imagens e mais de 100 páginas. A publicação apresenta um breve texto curatorial, dados sobre a história dos computadores, glossário de palavras, artigos sobre música e computação, além de escritos de artistas que experimentavam com a intermidialidade desde antes da década de 1960, como John Cage.

Vista de 2020, quando sobrevivemos à uma pandemia diante de exposições virtuais e relações sociais mediadas primordialmente por tecnologias de informação, é interessante observar como a curadora, nas poucas palavras que emprega no catálogo, aponta que nada de heroico poderia se concluir da exposição, conforme os computadores "tampouco revolucionaram nem a música, nem a arte, nem a poesia, da mesma forma que revolucionaram a ciência." (REICHARDT, 1969, p. 5; trad. livre).

Algo que também é destacado no texto é a possibilidade de que a inserção de computadores no meio artístico iria atrair um espectro de artistas que nunca precisariam tocar em um quadro ou um pincel, como cientistas executando programas de computador produtores de imagens que não tinham nenhum propósito senão experimentar no campo da estética eletrônica.

Dentre os projetos computacionais apresentados na exposição, destaca-se aqui The Colloquy of Mobiles, de Gordon Pask. Consistia em um grupo de objetos autômatos, os mobiles individuais, que eram projetados para conversar e se engajar na construção de um discurso, competindo e cooperando para aprender um sobre o outro. 0 discurso era projetado para evoluir em muitos níveis ordenados em uma hierarquia de controle e uma hierarquia de abstração. Era também projetado que o espectador poderia se unir ao discurso e influenciar o que estava acontecendo. Na proposição da obra, identifica-se o estímulo à uma cultura participativa mediada por tecnologias da informação em um ambiente projetado para um excesso de experiência cognitiva.

No catálogo, o que se versa sobre a obra parte da afirmação de que um ambiente esteticamente potente é um ambiente de qualquer tipo (sonoro, tátil, verbal, visual), no qual as pessoas se permitem curtir [enjoy]. 0 ambiente serviria para dar forma à essa curtição. 0 texto afirma que o artista seria potencialmente um formulador desse ambiente, mas que a qualidade de potência estética estaria primeiramente localizada na relação entre o ambiente e o espectador. 0 projeto Colloquy of Mobiles afirmava buscar estabelecer tal ambiente ativo e reativo:

1- De acordo com Burnham, houve destruição de objetos no transporte da exposição para Washington e a própria curadora não concordou com o modo que a exposição circulou no território norte-americano. 


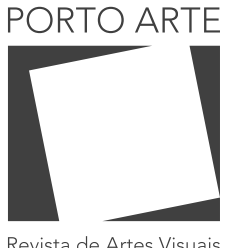

v. $25 n .43$ Jan/jun 2020 e-ISSN: 2179-8001
Um ambiente esteticamente potente encoraja que o ouvinte ou observador explore, aprenda e forme uma hierarquia de conceitos para se referir a tal ambiente; além disso, é o ambiente que guia a exploração do espectador por um sentido, fazendo ele participar e em qualquer ritmo ver a si mesmo refletido no próprio ambiente. (PASK, 1969, p. 34; trad. livre).

Criar um ambiente informacional, todavia, não significa necessariamente se engajar com autômatos, ainda que tal meio de engajamento fosse sintoma de uma crescente informacionalização da sociedade e do seu modo de pensar. No tópico subsequente do artigo, ao se observar a exposição Information, veremos como a curadoria encontrou, também sem computadores em si, uma experiência situada em uma dinâmica que não separava o cognitivo do sensorial ou o mental do corporal (como certas linhas cibernéticas alinhadas com o cartesianismo o fizeram, das quais tomaram distância cientistas como Francisco Varela e Humberto Maturana ao fundamentarem, nos anos 1970 e 1980, uma nova geração da jovem ciência navegacional).

\section{Information}

Em 1970, no MoMa, os loops de feedback entre arte e informação ganharam palco do outro lado do Atlântico, no epicentro do circuito artístico internacional. "Information" (1970), como apresenta seu curador Kynaston McShine (então há dois anos atuando no Departamento de Pintura e Escultura do museu), foi uma exposição "ampla e informal", "uma introdução para obras a partir das quais as preocupações estéticas dos anos 1970 irão emergir.- (MCSHINE, 1970, n.p.).

No catálogo, o mundo da arte é apresentado como se constituindo, naquele momento, principalmente através do conhecimento gerado pela visualização de reproduções e pela disseminação de informação em periódicos. Tal mundo também é apontando como afetado por satélites, filmes, televisão e pela aviação comercial, a qual permitia os artistas se internacionalizarem e trocarem com seus pares em uma velocidade sem precedentes, sem que necessariamente se encontrassem nos "centros da arte", como Paris e Nova Iorque.

As palavras escritas por McShine (1970, p. 141; trad. livre) no catálogo são medidas e austeras, segundo ele, intencionalmente:

Meu ensaio está realmente nas galerias e no todo desse volume. [] Portanto, esse livro é essencialmente uma antologia, considerado como um adjunto necessário à exposição. Contrário à tese de McLuhan, os livros ainda são um meio de comunicação basilar e talvez estejam se tornando ainda mais importantes, dado que o mundo se tornou a "vila global". 


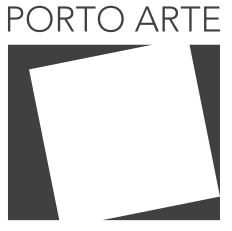

Revista de Artes Visuais

$\vee 25 n .43$

Jan/jun 2020 e-ISSN: 2179-8001

A publicação adotou uma proposta inovadora, ao não apenas ser utilizada para declarações verbais, descrição e apresentação das obras, apresentando-se como um meio para intervenção dos artistas (aparte ou sobreposta às suas obras2) e dos espectadores (algumas páginas foram deixadas vazias para o leitor colocar seus próprios textos e imagens). Além disso, uma série de imagens sem legenda (recortes de jornal, imagens de televisão, arquivos etc.) se encontra disposta sem explicação.

Como preocupações curatoriais expressas através de perguntas postas no catálogo, estavam as "implicações imprevisíveis" para os sistemas estabelecidos diante dessas transformações informacionais. Para o sistema de arte, McShine lançava dúvidas quanto à natureza do ato colecionista diante de obras feitas no fundo do mar, no vazio de desertos ou no frio da Antártica. Ele também questionava a capacidade dos museus de responder à introdução de novas tecnologias como uma parte cotidiana de suas preocupações curatoriais. Não teria uma atenção para tal questionamento preparado melhor museus e curadores para os movimentos tectônicos provocados no terreno da arte pela COVID-19?

Considerando a exposição "apenas o começo" de algo que estava por vir após 1970, o show contou com cerca de 150 artistas de diversas nacionalidades que, nas palavras introdutórias do catálogo:

são parte de uma cultura que foi consideravelmente alterada por sistemas comunicacionais, tais como filme e televisão, bem como pela crescente mobilidade. Fotografias, documentos, filmes e ideias rapidamente transmissíveis, portanto, tornaram-se importante parte de seus trabalhos. Isso levou à uma troca intelectual e uma comunidade internacional de artistas (MCSHINE, 1970, n.p.; trad. livre).

Sua pesquisa para a exposição foi conduzida em viagens para Europa e América do Sul em 1969, contando com uma visita ao "Salão da Bússola" (1969), no MAM-RJ, de onde colheu para "Information" (1970) os artistas Cildo Meireles, Guilherme Vaz e Artur Barrio. Nos poucos parágrafos que escreve no catálogo, o Brasil é explicitamente mencionado quando o curador aponta a diversidade de material apresentada em "Information" (1970), que teria caráter possivelmente de rebelião devido às crises políticas, sociais e econômicas do mundo de então, onde "se você é um artista do Brasil, você tem pelo menos um amigo que está sendo torturado." (MCSHINE, 1970, p. 138; trad. livre). 0 curador questiona a relevância e significância, então, do trabalho de quem acorda e simplesmente aplica tinta retirada de um tubo e o coloca em uma tela.

A ação que ele encontra em comum entre a centena heterogênea de artistas escolhidos para a exposição é a de "pensar conceitos que são mais amplos e mais cerebrais do que a expectativa de um "produto" saindo do ateliê" (id., p. 139; trad. livre), estando menos interessados em "embalsamar a ideia em um objeto" e mobilizados 


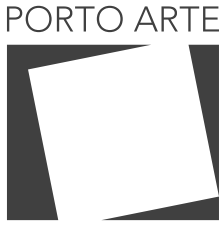

Revista de Artes Visuais

v. 25 ก. 43

Jan/jun 2020 e-ISSN: 2179-8001

em trocas de ideias que pudessem ir além das paredes que sustentam o cubo branco das galerias de arte. Estão inclusos na exposição, portanto, artistas que trabalham conceitualmente com o ambiente, com eventos e através do próprio corpo, como Hélio Oiticica, que expôs Ninhos.

Como curador, o papel de Kynaston McShine foi marcado por gestos inovadores que abandonavam a lógica de seleção curatorial centralista, tão pautada em obras prontas e no controle sobre todas elas, apesar dele ter se utilizado de recursos administrativos os quais, conforme McCarthy (2016), mimetizavam o formato e a linguagem de questionários corporativos ou governamentais pelo fato de requisitarem dados específicos sobre os projetos a serem apresentados. Os questionários acabaram provocando aos artistas que trabalhavam com informação a entrar em um jogo criativamente capitalizado nas obras resultantes:

A resposta de Jan Dibbet para a pergunta de McShine, "como você quer ser representado nesse catálogo?" foi uma concisa frase escrita à mão: "por esse papel". Outros artistas jogavam com o sistema. Hans Haacke propôs originalmente, para a obra MoMA Poll, que ele iria perguntar "uma questão sobre algum tema sócio-político atual". 0 conteúdo direto da obra e sua questão provocativa não foi revelado até o momento em que a obra estava instalada na galeria (MCARTHY, 2016, p. 29; trad. livre).

Por uma abertura descentralizada às situações inesperadas ou institucionalmente desconfortáveis, McCarthy propõe entender Kynaston McShine menos na linha do modelo "artista como curador" e mais a partir de um paradigma de economia informacional que saiu do âmbito nacional para o multinacional e adotou modelos de administração menos verticais:

Ao lado dessa mudança na concepção do papel do curador, onde tradicionalmente os processos de seleção são baseados em expertise e conhecimento, nós devemos tomar nota de sua ênfase em Information como um ambiente totalmente projetado, onde a tecnologia está integrada sem obstáculos com a experiência geral dos visitantes do museu (MCCARTHY, 2016, p. 30; trad. livre)

Como dito, essas mudanças resultaram em polêmicas. Afinal, MoMA Poll (1970) de Hans Haacke aplicou um questionário que levantava temas como a política de guerra norte-americana e a omissão política do governador de Nova Iorque e presidente do conselho do museu, Nelson Rockfeller. Vito Acconci3, por vez, transfe- 


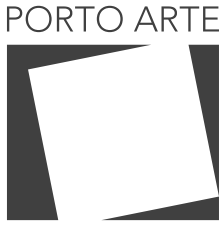

Revista de Artes Visuais v. 25 ก. 43 Jan/jun 2020 e-ISSN: 2179-8001

riu sua caixa postal para o espaço do museu durante o período de três meses, com suas correspondências sendo depositadas em uma caixa de vidro e coletadas pelo artista em intervalos variáveis.

\begin{abstract}
A polêmica interna se estendeu, após a abertura da exposição. Os documentos trocados entre o diretor John Hightower e David Rockfeller demonstram a insatisfação referente à algumas obras, em especial a de Hans Haacke (RUGGIERO, 2016, n.p.)
\end{abstract}

O próprio MoMa, assim, tornou-se uma vítima colateral dessa estratégia curatorial aberta pela "administração frouxa" dos dados de questionários sobre as obras que viriam a ser expostas. 0 museu contava com membros, em seu patronato, que mantinham laços com o complexo militar industrial e a indústria cultural de então, momento chave da Guerra do Vietnã (1955-1975). Certos artistas se viam, portanto, inserindo ruído em um símbolo do sistema de dominação vigente.

A exposição, portanto, desde o seu breve texto curatorial até às extensões da ação de Kynaston Mcschine, resultou em mais do que uma apresentação didática do que seria informação desde um ponto de vista pautado totalmente na ciência da cibernética ou nas teorias da informação e da comunicação para as artes, tornando-se na verdade um jogo confuso entre informação e ruído em uma instituição central no circuito das artes .

\title{
Software
}

Jack Burham é menos econômico, no seu texto curatorial, do que Kynaston McShine, levantando e desenvolvendo questões teóricas que envolvem informação, história da arte e cibernética. Apenas dois meses depois da exposição no MoMa, o Jewish Museum em Nova Iorque abriu uma outra exposição também engajada na discussão sobre a informação, mas com um outro foco, voltado para entender como as sensibilidades da arte poderiam se comunicar com "a área que cresce mais rapidamente no âmbito da cultura: sistemas de processamento de informação e seus dispositivos." (BURNHAM, 1970, p. 10).

Ao misturar pela primeira vez em um espaço expositivo os imensos computadores de então com artistas conceituais, Burnham utiliza o texto curatorial para se fazer entender não como propositor de uma exposição tecnológica ou de uma exposição de arte conceitual, mas como articulador de um ambiente capaz de fazer sensível o fato de que as tecnologias de informação devem ser compreendidas como "um ambiente penetrante muito necessitado da sensibilidade tradicionalmente associada com a arte." (BURNHAM, 1970, p. 14; trad. livre). Em outras palavras, seu interesse estava em dispor esses dois modos de sensibilidade programável em linguagem computacional ou artística, visando uma contaminação mútua capaz de 


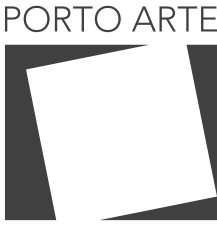

Revista de Artes Visuais

$\vee 25 n .43$

Jan/jun 2020 e-ISSN: 2179-8001

movimentar feedback loops estéticos e epistemológicos entre sistemas que, a longo prazo, não teriam como escapar um do outro.

Burnham afirma, assim, que o planejamento da exposição teve início em 1969 em reuniões que envolveram representantes tanto do campo das artes quanto do campo das tecnologias computacionais, comungando de um interesse pela cibernética e tendo como referência a exposição curada por Jasia Reichardt no fim da década de 1960.

O conceito de cibernética, todavia, é apontado no texto do curador como significando, naquele momento, "pouco ou nada" para os representantes das artes visuais e "uma ideia muito geral e ultrapassada" para os especialistas em computação. Considerando que a exposição de Londres tinha um caráter mais histórico, Burnham definiu como estratégia diferenciadora de Software o emprego de computadores no próprio espaço expositivo, algo que demandava um esforço técnico proporcional ao tamanho colossal dos computadores.

A cibernética aparecia como o germe de algo que já se expandira e modificara para além de suas determinações originais, não mais como uma teoria unificada sobre os níveis de controle e tipos de mensagens usadas por máquinas e entidades vivas para se comunicar:

Isso permanece como uma definição ideal, ainda que inversa, dado que a indústria nos faz ver que, na verdade, foram os seres humanos que se adaptaram às rotinas das máquinas inumanas. 0 que pouco se percebe é que a maior parte dos negócios, de qualquer tamanho, tiveram que se adaptar, mais ou menos traumaticamente, a diferentes padrões de administração e organização devido às estruturas de informação possibilitadas pelos sistemas de computadores. Então, em parte, Software direciona para si mesma as sensibilidades pessoais e sociais alteradas por essa revolução. Em geral, tais alterações foram internas, na forma de novos procedimentos e modos de se lidar com a realidade física, ao invés de respostas puramente físicas (BURNHAM, 1970, p. 11; trad. livre).

Os computadores em "Software" (1970) não seriam, para o curador, obras de arte, mas transdutores: meios de levar informação que poderiam ter ou não relevância nas artes. Sua expectativa era gerar uma interação entre os espectadores e as máquinas, uma interação que julgava ser pobre diante da riqueza da interação possível entre humanos, mas que marcaria a importância do diálogo, na arte, como um evento consciente e ambientalmente situado. 冈Outro objetivo de Software é deixar claro que a arte em si mesma é uma forma de diálogo intermitente. Nós estamos tentando fazer desse senso de diálogo um evento consciente.囚 (BURNHAM, 1970, p. 12). Tampouco as fotografias e material impresso pelos artistas conceituais presentes na exposição eram 


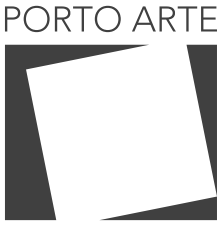

Revista de Artes Visuais

$\vee 25 n .43$ Jan/jun 2020 e-ISSN: 2179-8001

colocados como arte e sim como contexto e conceito, ambiente e evento programado.

Ao nomear a exposição de Software, o curador aponta um desejo de minar expectativas e hábitos comuns dos espectadores em exposições de arte, afirmando como cada vez mais as obras de arte não se reduziam à presença material e institucional do espaço das galerias. Burnham afirma como, naquele tempo, a estética ia se definindo a partir de procedimentos de planejamento e orçamento, menos interessados nos produtos finalizados, com os meios se tornando os fins.

Software e Hardware eram termos que ele acreditava que poderiam ser ressignificados a partir da sua inserção no ambiente das artes, refletindo-se no tradicional dualismo entre mente e corpo, característico do racionalismo cartesiano. Na computação, hardware inclui componentes como processadores, memórias, telas, equipamento de comunicação e placas de computadores. Os softwares seriam os programas armazenados, com propósitos gerais ou especiais, em linguagem computacional.

Filosoficamente, ele apontou que o dualismo software e hardware parece ser uma forma de neoplatonismo, ou seja, do conhecimento que se crê existir livre dos efeitos da firmação sensorial direta. Essa especulação se fez tão provada quanto pouco lembrada após os anos 1990, com a emergência no campo da cultura do conceito de ciberespaço, através de teóricos como Pierre Levy (1997), embebidos por tal neoplatonismo. Como um sistema, hardware e software interagem e determinam a estrutura um do outro. Software, em seus diversos sentidos, teria a ver com questões do comportamento, enquanto hardware com questões do corpo (espelhando um velho binarismo ocidental).

A noção problemática do conceito de software é julgada central pelo curador para se reconsiderar noções históricas de arte, ampliando seus meios e ambientes, bem como se voltando para o significado e o seu enquadramento sobre as obras, que passavam a ser vistas mais como signos, códigos e programas:

As mensagens dos artistas são frequentemente ignoradas por um não participante ou por alguém que precisa de treinamento para responder à certas pistas. Nesse sentido, a ideia de Software se detrai da noção de arte como um sistema de expectativas tangíveis e signos pré-digeridos. Ao invés disso, Software é sobre experienciar sem as pistas mentais da história da arte. Aqui se diz: 凶sinta suas respostas enquanto você as percebe de uma nova forma ou interage com algo ou alguém em uma situação incomum冈. Por essa razão, Software concerne à aparência perceptível do objeto de arte apenas uma fração da estrutura comunicacional que cerca qualquer arte. A introspecção, ao invés da inspeção, é o ponto do show (BURNHAM, 1970, p. 12; trad. livre).

Em um tempo de expansão dos problemas de magnitude relacionados ao armazenamento da informação, dados estatísticos e administração dos recursos ecológicos, Burnham via os profissionais da arte sendo confrontados pelo computador: a tecnolo- 


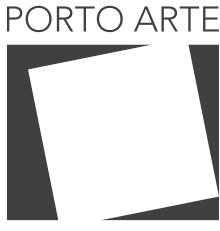

Revista de Artes Visuais v. 25 ก. 43 Jan/jun 2020 e-ISSN: 2179-8001

gia apresentava soluções práticas para que se pudesse lidar com um nível crescente de informação, produzindo um paradoxo onde não se podia mais sobreviver sem elas: "tão perigosas quanto os problemas que buscam resolver".

Nós podemos nos perguntar se as gerações futuras de sistemas de informação serão usadas com mais sensibilidade do que o rádio e a televisão foram usados até agora. Aparentemente, dado que a estética está removida dos confins apertados do Mundo da Arte, ela se vê na infusão de implicações biológicas, éticas, políticas que são esmagadoras, mas de qualquer forma essenciais (BURNHAM, 1970, p. 14; trad. livre).

Tal preocupação parece dialogar com a atualidade, onde a arte, a curadoria e os museus se fazem presentes na vida das pessoas como um instante dentre timelines de redes sociais e "fluxos informacionais". A arte durante a pandemia aparece em meio à fisicalidade temperamental do medo que se faz sentir tanto através da estética da (des) informação quanto da dinâmica biopolítica da disseminação viral.

Diversas questões e problemas técnicos apresentados na exposição de 1970, todavia, resultaram naquele momento em uma dissonância entre as questões levantadas por Burnham, a recepção da exposição e o que se propunha no texto dela.

Em 1980, dez anos depois de Software e antes do boom da Internet, em um texto chamado "Art and Technology: The Panacea That Failed", Burnham aponta diversos problemas na exposição: um filme que era exibido logo na abertura foi destruído em uma disputa entre os diretores e os produtores, perdendo 5 minutos do que havia sido previamente criado; computadores com programação falha impossibilitaram que os visitantes pudessem realizar uma das proposições mais inovadores dispostas no catálogo, que seria a impressão, no espaço expositivo, de um catálogo montado pelo próprio visitante com um computador (um servente, segundo a administração do museu afirmou para Burnham, teria causado um curto-circuito em um dos computadores justo na véspera da exposição).

Burnham aponta como tais problemas serviram aos tradicionais críticos de Nova Iorque como munição para a defesa dos velhos meios, pensamentos e tecnologias, tendo o diretor do museu, Karl Katz, perdido o seu cargo um mês após a desmontagem. Entre o que vislumbrou o texto curatorial, a limitação técnica e logística que se materializou no espaço expositivo e a recepção crítica da exposição naquele momento, resta um curioso e relevante ensaio sobre o ambiente informacional e as interlocuções que se foram constituindo entre arte e tecnologia, por vezes obliteradas da história da arte. 


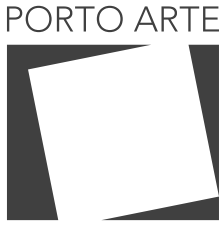

Revista de Artes Visuais

$\vee 25 n .43$

Jan/jun 2020 e-ISSN: 2179-8001

\section{Arteônica}

Destaca-se, por fim, a exposição "Arteônica" (1971) com a curadoria de Waldemar Cordeiro. Ainda que não se trate do primeiro evento no Brasil que traga como tema os sistemas comunicacionais que envolvem a cibernética e as teorias da informação (então já criticamente enquadradas pelo debate entre concretismo e neoconcretismo no país), é relevante pelo fato de que o tema está propriamente marcado por um engajamento computacional direcionado pelos artistas e cientistas participantes4.

Cordeiro é considerado um pioneiro da arte computacional na América Latina, tendo representado o Brasil na exposição "Cybernetic Serendipity" (1968). Antes disso, vale ressaltar, ele foi um dos expoentes do movimento de arte concreta que se desenvolveu nos fins da década de 1940. No texto da exposição Arteônica, ele aponta o concretismo como "antecedente metodológico" da arte computacional, ocorrendo no período de intensa industrialização nas áreas urbanas do país, levando-o a afirmar que "a arte concreta foi no Brasil a única que utilizou métodos digitais para a criação" e que ela "forneceu algoritmos largamente utilizados para comunicação através de meios industriais de produção." (CORDEIRO, 1971, n.p.).

Na década de 1960/1970, Cordeiro afirma que a arte concreta, bem como a arte cinética e outras "artes sintáticas" do pós-guerra viviam uma "profunda crise" em razão do aparecimento de uma cultura popular de massa distribuída através de meios eletrônicos de comunicação, sendo o Pop, o novo realismo e a nova figuração reações conservadoras a esse fenômeno.

A arte, para Cordeiro, teria seu próprio sistema de comunicação e informação e se fazia cada vez mais obsoleta conforme limitava sua natureza a meios que não dialogavam com o ritmo das intensas transformações tecnológicas. Ficavam, portanto, "aquém da demanda cultural quantitativa e qualitativa da sociedade moderna".

Cordeiro destaca em seu texto curatorial como a arte tradicional de então era consumida principalmente através de meios mecânicos e eletrônicos, reproduções, em uma "comutação comunicativa" que implicava em perda de informação plástica, um processo que julgava se reverter igualmente no Pop: a tradução para a tela de mensagens de comunicação de massa degradava, para Cordeiro, o nível informativo.

Ele via na arte eletrônica e digital a possibilidade das práticas artísticas não mais "setorizarem o ambiente e a semântica da experiência artística": o consumo da obra não deveria depender nem de um conhecimento específico prévio de repertórios da História da Arte, nem tampouco do enquadramento de um museu.

\footnotetext{
4- Em 1969, A Bienal de São Paulo, também conhecida como Bienal do Boicote, trouxe um setor chamado Arte e Tecnologia. O Salão da Bússola foi a alternativa que os artistas encontraram para a Bienal de São Paulo naquele mesmo ano. Ocorreu no MAM, promovido por uma empresa de um cearense atuando ramo comunicacional carioca e propunha o tema "Comunicação é inovação", ainda que o tema tenha sido extrapolado pelas propostas. Em 1970, O Serviço de Divulgação e Relações Culturais dos EUA expôs na Minigaleria da biblioteca do USIS, em São Paulo, uma exposição chamada "Computer Plotter Art", com 12 trabalhos feitos com computador nos EUA, tendo Cordeiro entrado na exposição com as obras da série Derivadas, com ampla divulgação da imprensa. Além disso, os textos críticos da década de 1950 corriqueiramente relacionam as afinidades entre os concretistas e as teorias da cibernética.
} 


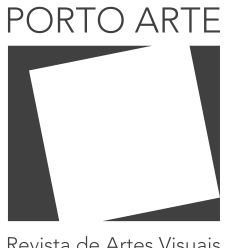

v. $25 n .43$ Jan/jun 2020 e-ISSN: 2179-8001
A setorização comunicativa e informativa conflita com o caráter interdisciplinar e integrado da cultura planetária. A simulação reproduz com eficaz rapidez a produção artística tradicional, exaurindo-a, esvaziando-a, fornecendo a radiografia e os elétrons do seu cadáver, o que vale por uma certidão de óbito do misoneísmo. Essa tendência, embora lance mão de recursos vastos, se autolimita à setorização já por nós apontada a respeito do diagnóstico das possibilidades comunicativas da arte tradicional, embora nessa condição setorial promova inegavelmente uma operação iconoclasta altamente higiênica. 0 problema mais urgente não é, contudo, o de rivalizar com a arte tradicional, porquanto isso equivaleria a aceitar um campo de atuação já condenado à obsolescência definitiva (CORDEIRO, 1971, n.p.).

A arte eletrônica, nesse sentido, era considerada como uma via de superação da arte tradicional, aberta à uma "dinâmica nova" onde as obras poderiam ser interdisciplinares e amplamente distribuídas, realizadas em colaboração com cientistas e disseminadas através de meios de comunicação em massa, crendo nessa projeção um amadurecimento de suas investigações concretistas.

Uma das principais colaborações de Cordeiro foi com o físico Giorgio Moscati, que em 1968 era Diretor do Departamento de Física da FFCL-USP. Eles se conheceram nesse mesmo ano, com Cordeiro afirmando seu desejo de investigar o uso do computador nas Artes. Moscati relembra que Cordeiro demonstrava um interesse crítico e não modista pelo instrumento:

Lembro-me bem das reações de Cordeiro quando o levei para visitar um laboratório do Departamento de Física e sua surpresa ao ver como se podia manipular imagens na tela de um osciloscópio excitado por sinais elétricos harmônicos e deformando a imagem com imãs que desviavam o feixe de elétrons. Introduzi também Cordeiro a todo um mundo de imagens de origem técnica e científica como capas de revistas (Science e outras), figuras de caráter científico, e gráficos de funções matemáticas. Ouvimos também gravações de músicas geradas por instrumentos eletrônicos (uma técnica iniciada nos anos 30), ou compostas por computador. (MOSCATI, 1993, p. 9)

No entusiasmo dessas experimentações, reunidas poucos anos depois em Arteônica, Cordeiro aponta que a arte contemporânea vivia uma crise que encontrava no seu cerne as questões comunicacional e informacional, entendendo a informação como algo que constitui a comunicação como seu veículo de transporte, processamento e 


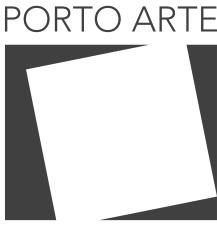

Revista de Artes Visuais

$\vee 25 n .43$

Jan/jun 2020 e-ISSN: 2179-8001

mecanização técnica. Os sistemas de comunicação contariam, assim, tanto com objetos artesanais, quanto com quadros e máquinas.

A informação artística, diga-se, não tinha para Cordeiro nada a ver nem com o que ele chama de kitsch da comunicação de massa nem com a "enfadonha, medíocre e inexpressiva" "cultura superior" acadêmica. É curioso como a fisicalidade e originalidade da obra de arte era apontada por ele como uma limitação ao potencial que os artistas ganhariam ao encontrarem formas de distribuir suas práticas em uma escala informacional que possibilitaria a informação artística atingir "os lugarejos mais remotos e isolados" do Brasil, sintonizando-se com o processo cultural que via ocorrer através das telecomunicações de maneira a permitir uma alteração da própria natureza da arte, mais do que meramente de sua escala:Artistas de formação basicamente tradicional pensam em resolver a crise comunicativa saindo das galerias e indo para a micro-paisagem urbana ou para o micro-paisagem regional, embrulhando montanhas por exemplo. Parecem não ter percebido que o obsoleto está na natureza da coisa e não na sua escala (CORDEIRO, 1971, n.p.).

Cordeiro projetou, então, que a arte encontraria nos meios eletrônicos uma otimização informativa e modos de processamento de imagem, para além de um valor artístico ou progressista de aderir a um virtuosismo técnico neoformalista, mas amplamente cultural: aumentando o número de fruidores, a situação da cultura se tornaria mais diversificada e o feedback mais complexo.

Ronaldo Brito, ainda na década de 1970, mas posterior ao falecimento de Cordeiro em 1973, escreve críticas ao pensamento que afinal ficou vinculado à imagem do "artista-curador eletrônico pós-concretista" depois de sua morte. Para Brito, Waldemar vislumbrou, nas artes computacionais, uma certa apoteose de possibilidades gestadas no concretismo. Por vez, o crítico afirmou que o "concretismo tinha uma crença ingênua e afinal capitalista na tecnologia em si, e tendia até para uma visão tecnocrata da cultura." (BRITO, 1977, p. 303).

Para Brito, a Teoria da Informação de Norbert Wiener e sua influência sobre Waldemar Cordeiro resultaram no concretismo ser guiado por um pragmatismo progressista, um racionalismo positivista, "com concepções cibernéticas das relações sociais". A eficácia da arte era vislumbrada no plano das informações de massa - "como criadora de matrizes e como método de investigação de processos semióticos ligados a esse plano" - com os artistas acreditando acriticamente na positividade de tal plano (BRITO, 1977, p. 306-307), no que resultava o trabalho de arte se tornar "apenas mais um meio de informação na rede de processos informacionais que caracterizam o 'ambiente contemporâneo'".

Julgada por críticos de arte da época como ingênuo e idealista, de fato o encontro entre arte computacional e Waldemar Cordeiro foi percebido como a realização de um projeto já desenhado no concretismo, por vezes entendido como uma racionalização e maquinização exagerada da arte, ao ponto de dispensar ao máximo possível os traços de humanidade. 


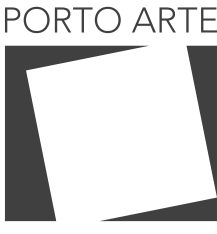

Revista de Artes Visuais

$\vee 25 n .43$

Jan/jun 2020 e-ISSN: 2179-8001

\section{Arte no ambiente informacional}

Especula-se aqui que é possível encarar as exposições de arte aqui recortadas conjuntamente (por abordarem a questão informacional na virada 1960/1970) como situadas no entremeio entre uma corriqueira compreensão de informação que a reduz ao primeiro nível da significação e uma compreensão artístico-cultural da informação como meio-ambiente. Ainda que estivessem fundamentadas em formulações conceituais sobre informação que hoje, por alguns, são consideradas desatualizadas, essas curadorias de obras de arte parecem apontar para o fato de que a modulação da informação pela arte e pela cultura direcionavam o pensamento para operar na dinâmica do denso meio-ambiente informacional.

Ao se inserir o conceito de informação nas artes, a referência científica mais explícita era o cientista da primeira geração cibernética, Norbert Wiener. No catálogo da exposição "Cybernetic Serendipity" (1968), por exemplo, apresenta-se o tema a partir do pensamento de Wiener, dedicando-se uma página à sua figura, citada diretamente. Através dele, os leitores do catálogo são apresentados à "ciência da navegação informacional" como consistindo em uma linguagem em desenvolvimento, capaz de atacar problemas comunicacionais e de encontrar um repertório próprio de ideias e técnicas de experiência e classificação.

Por vez, no catálogo da exposição "Software", o processamento da informação pela tecnologia era posicionado como determinante para se entender os limites da arte de então, apontando-se como o pensamento informacional influenciava o modo dos artistas se relacionarem com a criatividade e a percepção:

Assim pode ser que não seja, e provavelmente não é, a esfera dos computadores e de outros dispositivos de telecomunicação produzir arte como a conhecemos hoje; mas eles irão, de fato, ser instrumentais na redefinição de toda uma área de compreensão estética (BURNHAM, 1970, p. 11; trad. livre).

Em sintonia com tais discursos curatoriais, Waldemar Cordeiro, no texto da exposição "Arteônica" (1971), aponta para a existência de uma crise da informação na arte contemporânea. Essa crise seria uma consequência, para ele, da insistência da tradição em perpetuar a alienação resultante do desenvolvimento linear do processo artístico em um sistema fechado da Arte, o que entraria em conflito com o que ele chama de uma cultura planetária que faria uso de mídias eletrônicas e que, na arte, ele vislumbrava ser solução para abrir seu sistema para relações inesperadas.

Com suas articulações textuais atravessando do catálogo para o espaço expositivo, tais curadores agenciavam eventos de um momento em que, para Lucy Lippard, os artistas buscavam "reestruturar a percepção" conforme "sistemas e informação substituíram as preocupações formais tradicionais ... e os sistemas se colocaram sobre a vida." (LIPPARD, 1997, p. 15; trad. livre) 


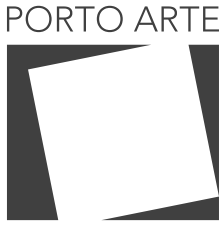

Revista de Artes Visuais $\vee 25 n .43$ Jan/jun 2020 e-ISSN: 2179-8001
Nas práticas conceituais, artistas como John Baldessari e Hans Haacke (expostos tanto em Information quanto em Software) afirmavam o interesse da arte pela e como informação:

Manifesto nos textos de artistas, nos discursos curatoriais e nos livros de críticos da virada 1960/1970 estava, portanto, o interesse artístico, conceitual pelas teorias da cibernética e da informação. Constatado isso, é relevante demarcar mais claramente o que é informação no contexto das primeiras décadas de cibernética, bem como observar o conceito desde uma abordagem atual.

Como referência científica sobre o tema, a noção de informação utilizada nos catálogos segue autores como Norbert Wiener: informação é definida pela relação entre sinal e ruído; como medida estatística de incerteza ou entropia de um sistema; como algo que implica um relacionamento não linear e não determinista entre os níveis microscópicos e macroscópicos de um sistema físico.

Tal definição é explicitamente subordinada, para Terranova (2004, p. 59), às demandas técnicas da engenharia da comunicação e mais especificamente aos problemas impostos por canais comunicacionais da época. O conceito de informação na metade do século XX dependia da problemática reprodução de um impulso ou sinal fraco através de uma variedade de diferentes canais. Os teóricos da primeira geração cibernética descreveram informação, desse modo, através de uma função matemática que poderia ser usada para maximizar a transmissão de um sinal através do canal.

Essa medida logarítmica ainda hoje é fundamental para os projetos de todos os dispositivos comunicacionais - dos telefones celulares aos computadores. Os sinais de todo tipo nos últimos trinta anos têm, por vez, convergido através principalmente da distribuição por meio dos feixes de luz de fibra óptica. Com a cultura cada vez mais pautada em uma dinâmica informacional, a comunicação crucialmente se vincula ao problema do ruído e gera uma política cultural que traz atritos entre o que se tem como estabelecido e o que é improvável. Nessa dinâmica, os fluxos de informação deslocam a questão da representação linguística e da identidade do centro das disputas culturais, favorecendo problemas mutantes e em movimento dentro de topologias imersivas e multidimensionais:

Dado que a teoria da informação estabelece os seus pilares teóricos a partir da termodinâmica e da mecânica estatística, ela entende os processos materiais como implicando uma relação não linear entre estados macro [...] e estados micro [...]. Isso tem uma consequência dupla para a nossa compreensão das políticas culturais da informa- 


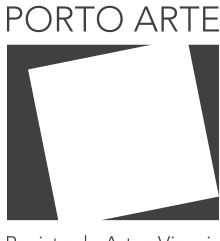

Revista de Artes Visuais

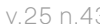

Jan/jun 2020 e-ISSN: 2179-8001

ção: por um lado, ela implica uma mudança da representação para a modulação eu enfatiza o poder do que permanece em mutação e em divergência; por outro lado, ela localiza a dinâmica informacional fora do espaço perspectivista e tridimensional da modernidade, em direção à uma topologia imersiva, multidimensional e transformativa (TERRANOVA, 2004, p. 28; trad. livre).

Dito isso, não se acredita aqui que as curadorias mencionadas conseguiriam, mesmo que talvez tentassem, subsumir a Arte às concepções científicas de informação e comunicação daquele período, ainda que fizessem referência explícita a cientistas como Norbert Wiener ou Marshall McLuhan em seus catálogos, promovendo interlocução entre arte e ciência, justamente em um período de experimentações (por vezes fracassadas ou anedóticas) de legitimação mútua entre ambas.

O que deve ser considerado para se pensar sobre arte e informação no pós-Segunda Guerra Mundial é que a Arte, ainda antes da guerra, da cibernética e das teorias modernas das informações, já contava com experimentos que ensaiavam, sem definir nos moldes clássicos dos cientistas, uma abordagem da informação como meio-ambiente, como mais do que um problema entre sinal e ruído, significação e representação.

Isso se fez mais especificamente perceptível a partir da personalidade precursora das práticas artísticas de Marcel Duchamp. Tal artista, através de processos materiais implicados em relações não lineares entre o contexto da subjetividade individual e o contexto do sistema de artes, ensaiou uma mudança da representação para a modulação5 e exerceu o poder da divergência, bem como a prática de uma geometria não-euclidiana, topológica e transformativa (ADCOCK, 1984), exatamente as características do meio-ambiente informacional contemporâneo destrinchadas por Terranova6.

Ou seja, além das próprias referências que os curadores e artistas da virada 1960/1970 buscavam nas ciências, contava-se no sistema das artes com vetores de referência dos seus próprios agentes, ainda que tais referências fossem descontinuadas, obliteradas ou pouco analisadas criticamente a partir do interesse pela questão informacional.

Conforme Terranova, os fluxos informacionais que se intensificaram a partir de tecnologias de distribuição e reprodução no século XX implicaram em uma crise política e linguística da representação, tanto na cultura quanto além dela, conforme modelos matemáticos estatísticos e não euclidianos reduziram a homogeneidade do espaço tridimensional e da perspectiva linear. As transformações produzidas entre arte, conceito

\footnotetext{
5- A modulação, na Fisica, é definida por uma operação de interação física realizada em um relais amplificador, em número infinito de estados. Trata-se de uma operação pela qual um sinal de fraca energia atualiza, com um certo número de graus possíveis, a energia potencial de um certo campo.

6- Ao se influenciar pelas abordagens topológicas do matemático e filósofo Henri Poincaré, abandonar a pintura e fazer iconoclastia com ready-mades, Duchamp enfatizou como a própria materialidade do processo de pintura era "ready-made", dado que a tinta era manufaturada industrialmente. De acordo com Judovitz (p. 127), Duchamp sugere em suas reflexões sobre os ready-mades que o exercício desse conceito está associado com pensar a pintura como um processo material, como meio ao invés de fim, destacando como os componentes materiais são instrumentais na determinação de como os artistas se apropriam e usam deles.
} 


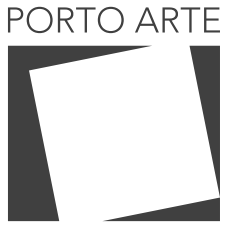

Revista de Artes Visuais v. 25 ก. 43 Jan/jun 2020 e-ISSN: 2179-8001 e espaço, ainda na obra de Duchamp, parecem ressoar exatamente nas transformações que Terranova aponta como se dando na sociedade de forma abrangente:

É esse espaço vazio organizado por uma perspectiva tridimensional que sustenta a dinâmica psíquica da identificação, mas também a possibilidade da representação linguística do self e dos outros, conforme são observados através de tal espaço. 0 espaço, pressuposto e engenhado por uma perspectiva informacional, expressa um desafio radical para a representação - e assim para toda a política cultural baseada em identidade e diferença. Não é só que todas as identidades e diferenças são reconfiguradas como macroestados ou médias que dependem de uma composição muito mais fluída e mutante. É também que toda a configuração do espaço dentro da qual tais políticas foram concebidas passa por uma mudança de foco (TERRANOVA, 2004, p. 36; trad. livre).

O espaço deixou de ser tridimensional e representacional e passou a ser informacional não exatamente quando passou a ser computado por máquinas, mas quando se emaranhou em uma dinâmica de excesso de dados sensoriais, um campo de deslocamentos, mutações e movimentos que não fundamentam as ações do sujeito, mas as decompõem, recompõem e o fazem se mover em um campo de intensas mediações.

Práticas conceituais na virada 1960/1970 inundaram o establishment das artes não exatamente por incorporar um modo de programar obras com computador, mas por arriscar uma abertura ao jogo entre espaço, informação e experiência corporificada (por mais que certos artistas conceituais europeus, norte-americanos ou paulistas tendiam, pelo viés da cultura ocidental, a entender mente e corpo como separados).

Era com bastante receio que a dimensão computacional desse processo se colocava como questão para teóricos e artistas, portanto não faltavam agentes da cautela e guardas de fronteira. Ao mesmo tempo em que identificavam a relação entre mediação maquínica e conceito, temiam que o processo artístico fosse reduzido à fisicalidade e ambiente da máquina, desvirtuando propósitos específicos da arte em sua pretensa autonomia.

No influente ensaio de Sol Lewitt, "Paragraphs of Conceptual Art" (1968, p. 12; trad. livre), isso fica claramente indicado: nos parágrafos iniciais ele afirma que "na arte conceitual a ideia do conceito é o aspecto mais importante da obra ... a ideia se torna a máquina que faz a arte"; para depois apontar o perigo de que "novos materiais são uma das grandes aflições da arte contemporânea ... o perigo é, penso, tornar a fisicalidade dos materiais tão importante que se torne a ideia da obra (outro tipo de expressionismo)".

No Brasil, os feedbacks loops tensos entre o concretismo dos paulistas e o neoconcretismo dos cariocas foram alimentando e gestando na arte brasileira um ambiente dotado de singularidades e de um corpo próprio diante do sistema global, mesmo 


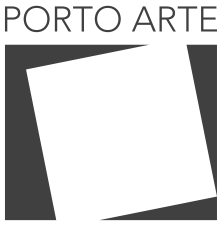

Revista de Artes Visuais

$\vee 25 n .43$

Jan/jun 2020 e-ISSN: 2179-8001

antecipando desvirtuações, soluções, ilusões e descontentamentos à aflição de Lewitt entre o pensamento mediado feito arte e a materialidade da mediação desse pensamento como risco de um novo expressionismo. Dois anos depois do texto de Lewitt, Hélio Oiticica participa com ele de "Information" (1970), encontrando-se já saturado desse debate tão comum aos cariocas e paulistas na virada 1950/1960.

Com isso, vemos como essas tensões no feedback loop entre os sistemas de informação e o sistema das artes se manifestavam nos textos curatoriais de quatro exposições significativas para o período em que tais relações ganharam importância nos mais legitimados espaços das artes visuais.

Mais do que aparentarem meramente ser informadas por teorias que não tinham como escapar de citar e se influenciar, tais curadorias eram também afetadas por uma linha de fazer artístico que borrou fronteiras entre informação e experiência estética mesmo antes da Segunda Guerra Mundial, formando caminhos que espelhavam tanto possibilidades quanto descrédito.

\section{Considerações finais}

As exposições selecionadas são notadamente heterogêneas tanto em si mesmas (contando com diversidade grande de propostas e artistas) quanto entre si (no recorte do artigo). São meio-ambientes informacionais que renderiam, cada uma, uma série de artigos. Com computadores ou sem computadores, com cientistas ou com artistas conceituais, encontramos no recorte uma linha comum atravessar: a percepção de um sistema de artes modulando a densificação do ambiente informacional e a influência de programas e das imagens técnicas nos espaços e lugares da arte.

Todas as exposições acabaram lidando com olhares críticos suspeitosos diante tanto da incorporação de máquinas, quanto da "imaterialidade" dos trabalhos, da heterogeneidade confusa do discurso e da transformação da sensibilidade ambiental do cubo branco, ainda oculocêntrica e ascética. Certas falhas técnicas das proposições criadas favoreciam ainda mais uma consideração limitada das propostas e da realidade que vislumbravam os textos curatoriais.

De qualquer forma, tais exposições da virada $1960 / 1970$ pensavam as questões de informação e cibernética e se possibilitaram ser encaradas hoje como ensaios do meio-ambiente informacional, do intenso e confuso fluxo de informações que resultou em uma sociedade que gera valor a partir da mineração de dados, do trabalho cognitivo e sua exaustão, do excesso de informação e do ambiente tóxico resultante de disputas éticas, políticas e estéticas no âmbito de redes informacionais.

Para além de um interesse nos artistas e na informação, via-se também um crescente interesse pelo ambiente, pela relação entre ambiente e espectador. Nesse sentido, ganha um papel distinto a própria figura do curador, que então aparecia como uma marca nova do conhecimento imaterial e do labor cognitivo cuja exploração se tornou sem precedentes na era digital.

Talvez só agora, com a pandemia do COVID-19, o sistema de artes através de meios computacionais esteja encontrando uma disseminação de fato na escala imagi- 


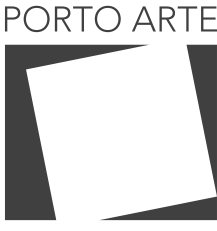

Revista de Artes Visuais

$\vee 25 n .43$

Jan/jun 2020 e-ISSN: 2179-8001

nada por Cordeiro, com grandes museus basicamente operando através da Internet e obras sendo acessíveis em qualquer lugar do país, como sonhou Cordeiro. Certamente não é pelo progressismo pragmático de Wiener que podemos entender isso, já que é justamente a persistência de uma lógica positivista e progressista diante do colapso ambiental o que mais assusta hoje.

0 artigo colabora com uma demanda de mais atenção para os percursos relacionais entre sistemas de informação e arte no século XX, bem como para o que se produziu, nos entremeios bem-sucedidos ou parcialmente fracassados entre arte tecnológica e prática conceitual nas artes. Sugere a importância de se multiplicarem formas de pensar como tais percursos ressoam com questões que envolvem topologia, ambientalidade, digitalidade e sensorialidade para o mundo após o boom digital dos anos 2000 e o que passa a se catalisar intensamente com a pandemia de 2020. É necessário realizar, como se fez aqui no artigo, aproximações e reflexões sobre arranjos que foram se formando no período e que podem ser rearranjados para multiplicar os vetores de força criadora diante da crise contemporânea.

\section{REFERÊNCIAS}

ADCOCK, Craig. Conventionalism in Henri Poincaré and Marcel Duchamp. Art Journal, v. 44, n. 3, p. 249-258, 1984.

ALLAN, Ken et al. Understanding information. Conceptual Art: Theory, Myth, and Practice, p. 144-168, 2004.

BURNHAM, Jack. Notes on art and information processing. Software-Information Technology: Its New Meaning for Art, p. 10-15, 1970.

BURNHAM, Jack. Art and Technology: The Panacea That Failed. The Myths of Information: Technology and Postindustrial Culture. K. Woodward. Wisconsin. 1980.

BRITO, Ronaldo. Vértice e Ruptura. In: AMARAL, Aracy A. Projeto construtivo brasileiro na arte (1950-1962). pp. 303-310. Museu de Arte Moderna do Rio de Janeiro, 1977.

GERE, Charlie. Digital culture. Londres: Reaktion Books, 2009

JUDOVITZ, Dalia; DUCHAMP, Marcel. Drawing on art: Duchamp and company. Minneapolis: University of Minnesota Press, 2010.

LIPPARD, Lucy R. (Ed.). Six years: the dematerialization of the art object from 1966 to 1972. Berkerley: University of California Press, 1997.

LEWITT, Sol. Paragraphs on conceptual art. Artforum, v. 5, n. 10, p. 79-83, 1967.

Lévy P. A Inteligência Colectiva-para uma antropologia do ciberespaço, trad. Lisboa: Instituto Piaget. 1997.

KYNASTON, Mcshine. Information. Nova Iorque: MoMA, 1970.

MCCARTHY, Jeremiah William. The Artist and the" Information" Machine: Conceptualism, Technology, and Design in 1970. 2016.

MCLUHAN, Marshall. Foreword. in: PORTER, Arthur. Cybernetics simplified. Londres: English University Press. 1969.

PARIKKA, Jussi. Insect media: An archaeology of animals and technology. Minneapolis: 


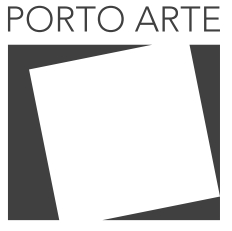

Revista de Artes Visuais

v. 25 n. 43
University of Minnesota Press, 2010.

REICHARDT, Jasia (Ed.). Cybernetic serendipity: the computer and the arts. Praeger, 1969.

SHANKEN, Edward A. Art in the information age: Technology and conceptual art. Leonardo, v. 35, n. 4, p. 433-438, 2002.

TERRANOVA, Tiziana. Network Culture: Cultural Politics for the Information Age. Londres: Pluto Press, 2004.

USSELMANN, Rainer. The dilemma of media art: Cybernetic serendipity at the ICA London. Leonardo, v. 36, n. 5, p. 389-396, 2003

WIENER, Norbert. Cybernetics or Control and Communication in the Animal and the Machine. Boston: MIT press, 2019. 


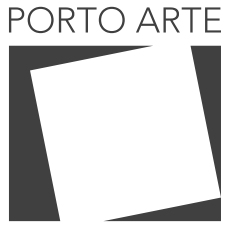

Revista de Artes Visuais

v. $25 \mathrm{n} .43$

Jan/jun 2020 e-ISSN: 2179-8001

\section{Ruy Cézar Campos Figueiredo}

Doutorando em Tecnologias da Comunicação e Cultura pela Universidade do Estado do Rio de Janeiro - UERJ. Mestre em Artes e Processos de Criação: Poéticas Contemporâneas pela Universidade Federal do Ceará. Bacharel em Audiovisual e Novas Mídias.

Texto recebido em: 24/05/2019

Texto aceito em: 08/06/2020

Texto publicado em: 30/06/2020 